Article

\title{
A Prospective Clinical Trial of Prolonged Fasting in Healthy Young Males and Females-Effect on Fatigue, Sleepiness, Mood and Body Composition
}

\author{
Boya Nugraha ${ }^{*}+{ }^{+}$, Amin Riat ${ }^{\dagger}$, Samaneh Khoshandam Ghashang ${ }^{\dagger}$, Luqman Eljurnazi and \\ Christoph Gutenbrunner \\ Department of Rehabilitation Medicine, Hannover Medical School, 30625 Hannover, Germany; \\ aminhajamer@gmail.com (A.R.); samaneh.khoshandam@googlemail.com (S.K.G.); \\ luqman_eljurnazi@yahoo.com (L.E.); gutenbrunner.christoph@mh-hannover.de (C.G.) \\ * Correspondence: boya.nugraha@gmail.com; Tel.: +49-511-532-9197 \\ † Equal contributed author.
}

Received: 30 June 2020; Accepted: 28 July 2020; Published: 30 July 2020

\begin{abstract}
Fasting during a long period (17-18 h/day) may affect daily performance. Fatigue is one of important parameters to observe for this effect. This study aimed to determine the effect of Ramadan fasting (RF) - particularly on fatigue in both young males and females. Sleepiness, mood-related symptoms (MRSs) and body composition (BC) were determined, too. Thirty-four young males and females were recruited and performed RF. They were assessed for fatigue, sleepiness, MRS and BC at T1 (one week before RF), T2 (mid of RF), T3 (last days of RF), T4 (one week after RF) and T5 (one month after RF). The assessments were done in the morning, except for fatigue and sleepiness, which were also assessed in the afternoon and evening of $\mathrm{T} 1$ to $\mathrm{T} 5$. This study observed numerous positive effects to RF. After they began fasting and compared to T1, participants experienced (1) significantly less fatigue; (2) small to large improvement of MRSs; and (3) positive changes relating to BC. RF did not appear to have a significant effect on participants' sleepiness scores. Ultimately, this study illustrates how prolonged fasting, like RF, benefits the youth, particularly by decreasing fatigue, improving MRSs and positively impacting BC.
\end{abstract}

Keywords: fasting; Ramadan; health; fatigue; mood; body composition

\section{Introduction}

Fasting has been practiced for centuries by billions of people worldwide. The benefits of different types of fasting have also been recorded. Intermittent fasting (IF) is a period of voluntary abstinence from food and drink without focusing on the type of food and drinks are consumed [1]. Studies show that IF is beneficial for weight loss [2], IF also reduces fat mass, but not skeletal mass in old females [3]. Studies also illustrate that IF reduces weight loss and insulin requirement in diabetic patients (both type 1 and type 2) [4], reduces inflammatory markers in cardiovascular diseases [5], results in improved peripheral and central blood pressure control in hypertensive patients with and without chronic kidney diseases [6] and reduces toxicity and facilitate effective chemotherapy in cancer patients [7]. IF could benefit against a different type of diseases related to aging $[8,9]$ and it has many other health benefits $[9,10]$. IF has also become a lifestyle in combination with exercise [11].

Ramadan fasting (RF) is one type of IF. The difference between RF and other types of IFs is that it is only performed during the month of Ramadan (a month the Islamic calendar year) and people engaged in RF must abstain from food, drink, sex and smoke from dawn to dusk. There are exceptions including for people who are sick, women during the menstrual periods and those who are 
traveling. Though RF is generally obligatory for Muslims, many studies have reported the benefits of RF. Studies have analyzed the effect of RF in patients with various conditions, such as diabetes [12,13], kidney-related problems [14] and asthma [15]. In patients, RF should be carefully monitored by health professionals. Other studies also reported the effect of RF on young males [16-18], workers [19], tennis players [20] and taekwondo athletes [21].

A long period of fasting could influence different aspects of the human body, including at genetic level [22,23] and its phenotypic manifestations; for example, one study showed the changing in health-related quality of life and body composition (BC) parameters [16]. Another study showed the alteration of creatinine levels during a long fasting period in young males, although it is still in health range [17].

Fatigue is one of the important factors to be determined for daily performance [24], as it is strongly related to poor physical performance [25], including during RF. Fatigue is defined as a subjective experience and includes such symptoms as rapid inanition, persisting lack of energy, exhaustion, physical and mental tiredness and apathy [26]. Therefore, fatigue could be one of the important factors to be determined during RF, as it could also influence daily performance, either at the office, school, university or any other activities.

Interesting results were also reported in a recent study that demonstrated the beneficial effect of fasting in the young male in relation to fatigue and health-related quality of life [16]. It was conducted during summertime in Germany which had a long fasting period (18-19 h/day). However, it had some limitations, including that it was performed only in young males and it was only assessed in the morning time. Meanwhile, the level of fatigue could be different between morning, afternoon and evening. It would be also of interest to determine the effect of RF in both sexes. Therefore, the main objective of this study was to determine the level of fatigue during RF, in both genders.

\section{Materials and Methods}

The local ethics committee of Hannover Medical School approved this study (Ethics No. 7242; Registration code of the trial: DRKS00017640). This study was in line with the Declaration of Helsinki. It was performed from May to July 2017. The RF itself was performed for 30 days (26 May-24 June 2017). Study center was Department of Rehabilitation Medicine, Hannover Medical School, Hannover, Germany. This study was evaluated at five different assessment time points (T1, T2, T3, T4 and T5) and in the morning, afternoon and evening (see Table 1).

Table 1. Study design of RF.

\begin{tabular}{|c|c|c|c|c|c|}
\hline & \multicolumn{5}{|c|}{ Time Point of Assessment and Assessment Parameters } \\
\hline & $\begin{array}{c}\text { T1 } \\
\text { (Baseline: } 1 \text { Week before RF) }\end{array}$ & $\begin{array}{c}\text { T2 } \\
\text { (Mid of RF) }\end{array}$ & $\begin{array}{c}\text { T3 } \\
\text { (Last Days of RF) }\end{array}$ & $\begin{array}{c}\text { T4 } \\
\text { (1 Week after RF) }\end{array}$ & $\begin{array}{c}\text { T5 } \\
\text { (1 Month after RF) }\end{array}$ \\
\hline $\begin{array}{c}\text { Morning } \\
\text { 07:00-10:00) }\end{array}$ & BC, FSS, ESS, HADS, BDI-II & $\begin{array}{l}\text { BC, FSS, ESS, } \\
\text { HADS, BDI-II }\end{array}$ & $\begin{array}{l}\text { BC, FSS, ESS, } \\
\text { HADS, BDI-II }\end{array}$ & $\begin{array}{l}\text { BC, FSS, ESS, } \\
\text { HADS, BDI-II }\end{array}$ & $\begin{array}{l}\text { BC, FSS, ESS, } \\
\text { HADS, BDI-II }\end{array}$ \\
\hline $\begin{array}{c}\text { Afternoon } \\
(13: 00-15: 00)\end{array}$ & FSS, ESS & FSS, ESS & FSS, ESS & FSS, ESS & FSS, ESS \\
\hline $\begin{array}{c}\text { Evening } \\
(19: 00-20: 00)\end{array}$ & FSS, ESS & FSS, ESS & FSS, ESS & FSS, ESS & FSS, ESS \\
\hline
\end{tabular}

Note: RF-Ramadan fasting; BC—body composition; FSS—fatigue severity scale; ESS—Epworth sleepiness scales; HADS-hospital anxiety depression scale; BDI-II-Beck's depression inventory-II.

\subsection{Participants}

Thirty-four healthy participants (male and female) were recruited. All participants were healthy (free from pain and psychiatric disorders). Most of them were students at Hannover Medical School. They were older than 18-year-old and planned to fast the whole month of Ramadan. All participants comprehended the English or German language. Participants were excluded if they broke the fast for more than 7 days. All participants participated in this study after signing informed consent. 


\subsection{Endpoints}

Fatigue was the primary endpoint and assessed by using the fatigue severity scale (FSS). It is a self-administered questionnaire with nine questions. Every question has statements that are scored from 1 (strongly disagree) to 7 (strongly agree) [27]. Sleep problems were assessed by using Epworth sleepiness scale (ESS). ESS is also a self-reported questionnaire with eight item questions. Every question can be scored on a 4-point measuring tape (0-3). Final score of ESS is the sum of 8 questionnaires which can range from 0 to 24 . The higher the ESS score, the higher that person's average propensity in daily life to daytime sleepiness [28]. FSS and ESS questionnaires were taken in the morning (between 07:00 and 10:00), afternoon (between 13:00 and 15:00) and evening (between 19:00 and 20:00). In the morning at all assessment time points (T1-T5), participants filled in ESS and FSS at study center. In the afternoon and evening, they did it outside study center (e.g., at university or home).

Mood-related symptoms (MRSs) were determined by using Beck's depression inventory (BDI)-II and hospital and anxiety depression scale (HADS). BDI-II is a self-administered questionnaire to measure the severity of depression with 21 questions. The total score of BDI-II ranges from zero to sixty-three. The higher the BDI-II score is, the more severe the depression [29]. HADS is also a self-reported questionnaire that consists of fourteen questions. Seven items are related to anxiety, and seven items are related to depression [26]. A score of 8 or more reveals anxiety or depression symptoms. BDI-II and HADS were determined in the morning at all assessment time points (T1-T5) at study center.

BC parameters were measured by using InBody 230 (Model MW160, InBody Co., Ltd, Seoul, Korea). The latter measurements include body fat percentage (BFP), body weight (BW), body water mass (BWM), skeletal muscle mass (SMM), body fat mass (BFM) and fat-free mass (FFM). This machine was also used to estimate basal metabolic rate (BMR). Body mass index (BMI) was calculated by measuring the height of the participants manually (using measuring tape) and calculated by using following formula: $\mathrm{BMI}=$ mass $/(\text { height })^{2}$; where mass in $\mathrm{kg}$; height in $\mathrm{m}$. BC parameters were determined only in the morning at all assessment time points (T1 to T5) at study center.

\subsection{Sample Size Calculation}

Sample size was calculated based on previous study [16] that showed partial eta square for fatigue (FSS; $\left.\eta^{2}=0.151 ;[16]\right)$ that resulted the effect size (ES) of $(\mathrm{f})=0.4217$. The type I error probability was set by 0.05 with power (ß) of 0.95 . It resulted to have at least 24 participants. Considering $25 \%$ of participants dropped out, the total sample size should be at least 32 participants.

\subsection{Statistics Evaluation}

The study objective aimed at assessing the level of fatigue before, during and after Ramadan in three different time points: morning, afternoon and evening. Depending on the distribution of the data, analysis of the primary endpoint was done by using either mixed-model ANOVA or Two-way Friedman ranked test. Secondary endpoints, like sleepiness, MRSs and BC parameters were also investigated. Depending on the distribution of the data, secondary endpoints were analyzed by using either ANOVA repeated measure or Two-way Friedman ranked test. The post hoc tests were performed, and significances were adjusted by using Bonferroni correction. Missing data were replaced by using mean imputation method. Kolmogorov-Smirnov test was used to determine the distribution of the data. Significance was set at $p<0.05$. SPSS 26 (IBM, New York City, NY, USA) was used to analyze the data.

ES for FSS and ESS were calculated by using following formula: $\eta^{2}=Z^{2} /(N-1)$.

ES for BC parameters and MRSs were calculated by using following formula: $\left(\mu_{1}-\mu_{2}\right) / S D$; $\mathrm{SD}=$ standard deviation. 


\section{Results}

\subsection{Recruitment of the Participants}

Sixty-eight people were asked to participate in this study. Fifty-two participants were invited, with 42 attending at T1. Due to several reasons, including sickness, time schedule and other reasons, only 34 participants remained as completers and is included in the analysis (Figure 1).

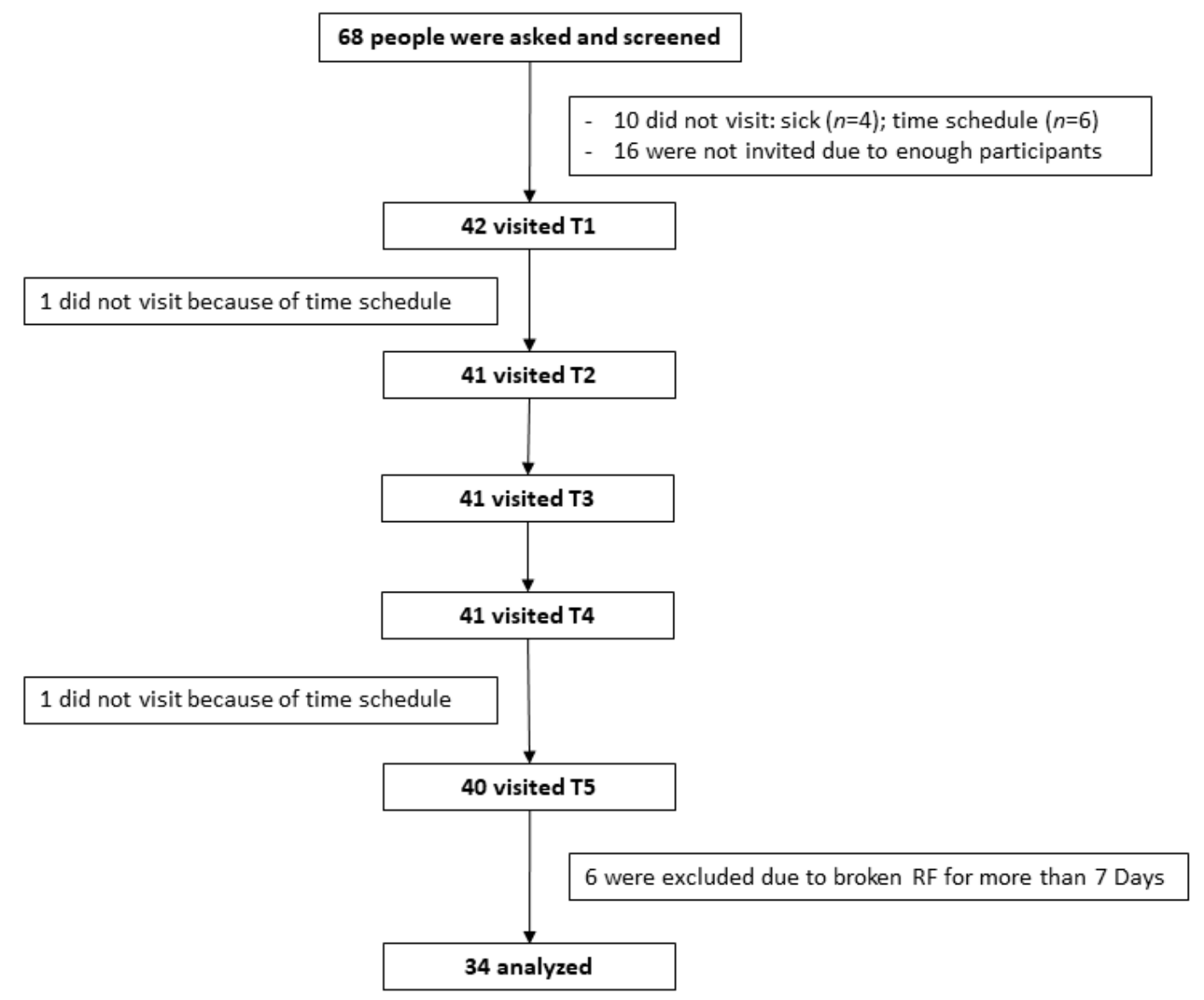

Figure 1. Flow chart recruitment of participants.

\subsection{Baseline Characteristics of Participants}

Table 2 shows the baseline characteristics of all participants. Additionally, statistics tests to compare male and female participants were performed. There were no significant differences in age and race between male and female participants. Fatigue, MRSs and sleepiness scores were not significantly different. As expected, almost all BC parameters between males and females showed significant differences, except BMI.

Table 2. Baseline clinical characteristics of participants.

\begin{tabular}{ccccc}
\hline & All Participants & Male & Female & $p$ \\
& $\boldsymbol{N}=\mathbf{3 4}$ & $\boldsymbol{N}=\mathbf{1 9}$ & $\boldsymbol{N}=\mathbf{1 5}$ & (Male vs. Female) \\
\hline Age & $25.1 \pm 0.8$ & $24.8 \pm 1.0$ & $25.5 \pm 1.2$ & 0.65 \\
Caucasian/Other & $23 / 11$ & $14 / 5$ & $9 / 6$ & 0.48 \\
\hline
\end{tabular}


Table 2. Cont.

\begin{tabular}{|c|c|c|c|c|}
\hline & $\begin{array}{l}\text { All Participants } \\
\qquad N=34\end{array}$ & $\begin{array}{c}\text { Male } \\
N=19\end{array}$ & $\begin{array}{l}\text { Female } \\
N=15\end{array}$ & $\begin{array}{c}p \\
\text { (Male vs. Female) }\end{array}$ \\
\hline \multicolumn{5}{|c|}{ Body Composition } \\
\hline BW (kg) & $72.0 \pm 2.3$ & $77.31 \pm 3.1$ & $65.3 \pm 2.3$ & $<0.01$ \\
\hline $\operatorname{BMI}\left(\mathrm{kg} / \mathrm{m}^{2}\right)$ & $24.8 \pm 0.6$ & $25.10 \pm 0.9$ & $24.4 \pm 0.8$ & 0.56 \\
\hline SMM (kg) & $30.0 \pm 1.2$ & $34.60 \pm 1.2$ & $24.2 \pm 0.8$ & $<0.001$ \\
\hline BFM (kg) & $18.4 \pm 1.2$ & $16.2 \pm 1.7$ & $21.1 \pm 1.5$ & $<0.05$ \\
\hline FFM (kg) & $53.6 \pm 1.9$ & $61.1 \pm 2.0$ & $44.2 \pm 1.4$ & $<0.001$ \\
\hline $\mathrm{BFP}(\%)$ & $25.4 \pm 1.5$ & $20.2 \pm 1.5$ & $31.9 \pm 1.6$ & $<0.001$ \\
\hline BWM (kg) & $39.3 \pm 1.4$ & $44.8 \pm 1.4$ & $32.4 \pm 1.0$ & $<0.001$ \\
\hline $\operatorname{BMR}(\mathrm{J} /(\mathrm{h} \mathrm{kg}))$ & $1528.5 \pm 41.4$ & $1686.0 \pm 85.3$ & $1324.7 \pm 30.3$ & $<0.001$ \\
\hline \multicolumn{5}{|c|}{ Mood, Fatigue, Sleepiness } \\
\hline Anxiety (HADS-A) & $6.2 \pm 0.6$ & $6.6 \pm 0.6$ & $5.9 \pm 1.1$ & 0.57 \\
\hline Depression (HADS-D) & $4.4 \pm 0.6$ & $4.8 \pm 0.7$ & $4.0 \pm 0.8$ & 0.49 \\
\hline Depression (BDI-II) & $10.9 \pm 1.3$ & $9.5 \pm 1.3$ & $12.7 \pm 2.3$ & 0.21 \\
\hline Fatigue severity scale (Median (IQR)) & $3.1(2.1-4.5)$ & $3.0(2.4-4.4)$ & $3.3(2.1-4.8)$ & 0.73 \\
\hline Epworth sleepiness scale (Median (IQR)) & $7.0(5.0-10.0)$ & $7.0(5.0-10.0)$ & $7.4(5.0-10.0)$ & 0.89 \\
\hline
\end{tabular}

Baseline data of age, race, BC parameters, mood, fatigue and sleepiness of all participants, only males and females. $p$-values were tested by using t-test or Mann-Whitney-U test (FSS and ESS).

\subsection{Fatigue and Sleepiness during RF}

Figure 2 demonstrates the pattern of fatigue (2A) and sleepiness (2B) scores at all times of the study in the morning, afternoon and evening. Significant differences were observed in fatigue scores $(p<0.001$; two-way Friedman rank test). The patterns of fatigue score, particularly in the morning tend to improve from baseline (T1) to T4 and turned back to the baseline level at T5. The pattern of alterations of fatigue in the afternoon and evening were similar (except at T3) and tend to decrease until T5.
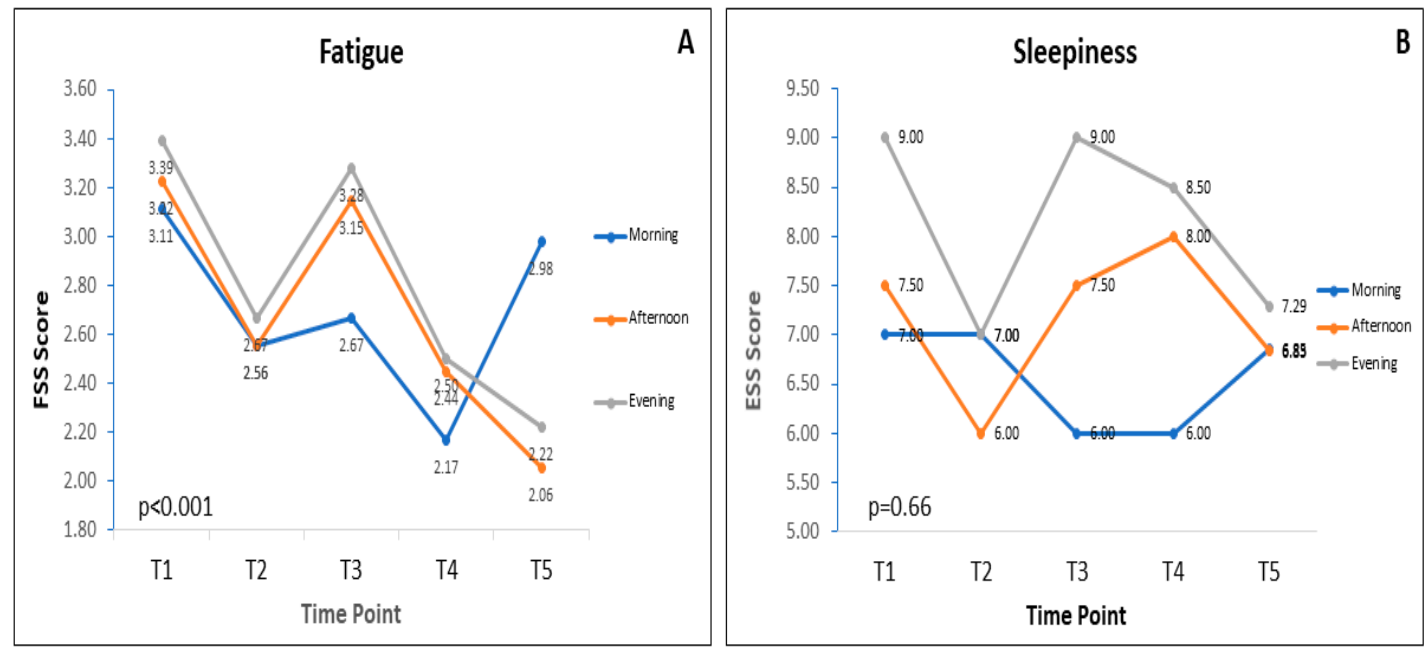

Figure 2. Patterns of fatigue (A) and sleepiness (B) scores during RF at T1 (one week before RF; $n=34$ ), T2 (mid of RF; $n=34$ ), T3 (last days of RF; $n=34$ ), T4 (one week after RF; $n=34$ ) and T5 (one month after RF; $n=34$ ). Both fatigue and sleepiness were assessed in the morning, afternoon and evening. Data presented as median.

There were no significant difference in sleepiness scores ( $p=0.66$; two-way Friedman rank test). The patterns of sleepiness scores in the afternoon and evening were similar.

Table 3 contains the data of each day-time group (morning, afternoon and evening). The significant differences were observed only in fatigue scores. Post hoc analysis showed that fatigue score was significantly different in the morning and evening. Specifically, significant differences in the morning 
were observed when comparing T1 and T4 $(p<0.05)$. In the evening, the significant differences were observed when comparing T1 and T5 $(p<0.01)$. No significant differences were observed in the sleepiness score.

Table 3. Fatigue and sleepiness scores during RF (all participants).

\begin{tabular}{|c|c|c|c|c|c|c|c|}
\hline & \multicolumn{5}{|c|}{ Time Point } & \multirow{2}{*}{\multicolumn{2}{|c|}{$p$}} \\
\hline & $\mathrm{T} 1(n=34)$ & $\mathrm{T} 2(n=34)$ & T3 $(n=34)$ & $\mathrm{T} 4(n=34)$ & T5 $(n=34)$ & & \\
\hline \multicolumn{8}{|c|}{ Fatigue severity scale; median (IQR) } \\
\hline Morning & $\begin{array}{c}3.1 \\
(2.1-4.5)\end{array}$ & $\begin{array}{c}2.6 \\
(2.2-3.9)\end{array}$ & $\begin{array}{c}2.67 \\
(1.4-3.9)\end{array}$ & $\begin{array}{c}2.1 \\
(1.2-3.9)\end{array}$ & $\begin{array}{c}3.0 \\
(1.2-4.2)\end{array}$ & $<0.05$ & \\
\hline Afternoon & $\begin{array}{c}3.2 \\
(1.9-4.4)\end{array}$ & $\begin{array}{c}2.6 \\
(1.8-3.7)\end{array}$ & $\begin{array}{c}3.15 \\
(1.6-4.7)\end{array}$ & $\begin{array}{c}2.4 \\
(1.2-3.8)\end{array}$ & $\begin{array}{c}2.1 \\
(1.2-4.0)\end{array}$ & 0.16 & $<0.001^{\S}$ \\
\hline Evening & $\begin{array}{c}3.4 \\
(2.1-4.6)\end{array}$ & $\begin{array}{c}2.7 \\
(1.7-4.4)\end{array}$ & $\begin{array}{c}3.28 \\
(1.5-4.6)\end{array}$ & $\begin{array}{c}2.5 \\
(1.3-4.1)\end{array}$ & $\begin{array}{c}2.2 \\
(1.2-3.6)\end{array}$ & $<0.01$ & \\
\hline \multicolumn{8}{|c|}{ Sleepiness (ESS score); median (IQR) } \\
\hline Morning & $\begin{array}{c}7.0 \\
(5.0-10.0)\end{array}$ & $\begin{array}{c}7.0 \\
(3.75-10.00)\end{array}$ & $\begin{array}{c}6.0 \\
(2.0-9.0)\end{array}$ & $\begin{array}{c}6.0 \\
(1.8-9.2)\end{array}$ & $\begin{array}{c}6.8 \\
(2.0-10.2)\end{array}$ & 0.37 & \\
\hline Afternoon & $\begin{array}{c}7.5 \\
(2.8-10.0)\end{array}$ & $\begin{array}{c}6.00 \\
(1.8-9.2)\end{array}$ & $\begin{array}{c}7.50 \\
(3.0-11.2)\end{array}$ & $\begin{array}{c}8.0 \\
(2.0-11.0)\end{array}$ & $\begin{array}{c}6.8 \\
(2.0-10.2)\end{array}$ & 0.44 & $0.66 \S$ \\
\hline Evening & $\begin{array}{c}9.0 \\
(5.0-11.0)\end{array}$ & $\begin{array}{c}7.0 \\
(3.8-10.0)\end{array}$ & $\begin{array}{c}9.00 \\
(3.0-13.2)\end{array}$ & $\begin{array}{c}8.5 \\
(4.5-11.2)\end{array}$ & $\begin{array}{c}7.3 \\
(3.8-11.2)\end{array}$ & 0.87 & \\
\hline
\end{tabular}

Note: ${ }^{\S}$ Friedman-rank test followed by post hoc-test with Bonferroni correction.

The effect of RF on fatigue and sleepiness is shown in Figure 3. The significant differences concerning fatigue could only be observed in the male in the morning (T1 vs. T4; $p<0.01$; Figure $3 \mathrm{~A}$ ); and female in the evening (T1 vs. T5; $p<0.05$; Figure 3C). Although no significant differences of sleepiness score, the authors also separately analyzed the data comparing the score of fatigue and sleepiness of male and female. This also shows in Figure 3. The data clearly shows that females tend to have higher values in both FSS and ESS. The significant differences between males and females was only observed in ESS scores in the morning at T4 (Figure 3D) and in the afternoon at T4 and T5 (Figure 3E).

Table 4 demonstrates the ES of FSS and ESS between T1 and T3. The results show that the ES of FSS and ESS between T1 and T3 in the morning, afternoon and evening time in all participants, in only females and males was small.

Table 4. ES of fatigue and sleepiness scores during RF in the morning, afternoon and evening between $\mathrm{T} 1$ and $\mathrm{T} 3$.

\begin{tabular}{ccccc}
\hline \multirow{2}{*}{} & & \multicolumn{3}{c}{ ES } \\
\cline { 3 - 5 } & & All Participants & Male & Female \\
\hline \multirow{3}{*}{ FSS } & Morning & 0.07 & 0.08 & 0.08 \\
& Afternoon & 0.01 & 0.03 & 0.26 \\
& Evening & 0.04 & 0.00 & 0.23 \\
\multirow{2}{*}{ ESS } & Morning & 0.07 & 0.08 & 0.01 \\
& Afternoon & 0.02 & 0.00 & 0.10 \\
& Evening & 0.00 & 0.00 & 0.05 \\
\hline
\end{tabular}

Note: ES—effect size; FSS—fatigue severity scale; ESS—Epworth sleepiness scale. 

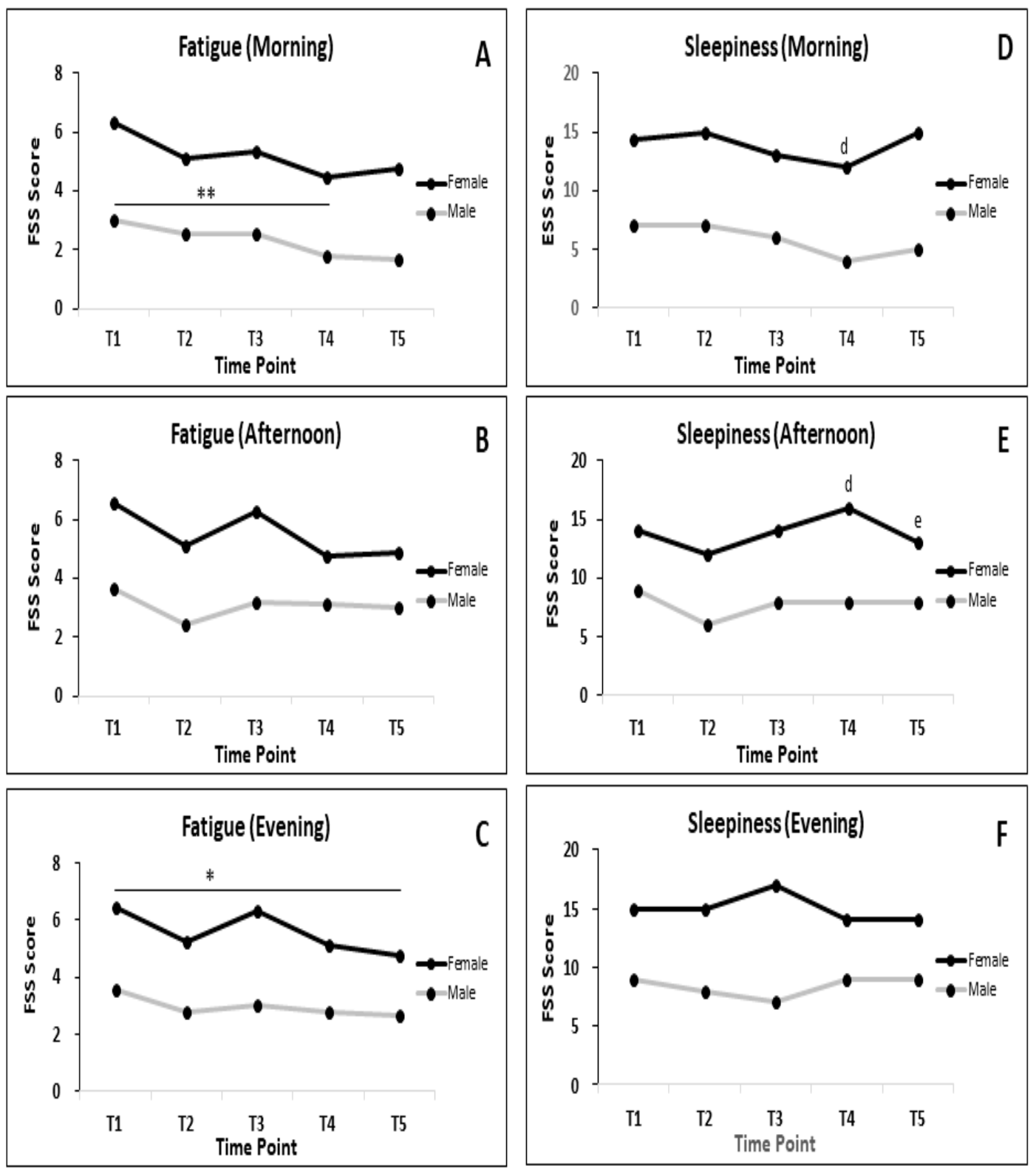

Figure 3. (A,D) Patterns of fatigue and sleepiness during RF in male and female in the morning; (B,E) afternoon and (C,F) and evening; (d,e) significant difference between male and female at T4 and T5, respectively. $n$ at each time point for male $=19$, female $=15$. Data presented as median. ${ }^{*} p<0.05$; ** $p<0.01$.

\subsection{MRSs during RF}

Figure 4 demonstrates the effect of RF on MRSs. Significant differences of depression score were observed when comparing T2 vs. T3 $(p<0.05)$ and T2 vs. T5 $(p<0.01)$ in all participants that were determined by using BDI-II (Figure $4 \mathrm{C}$ ).

Figure 4D-F show the pattern of MRSs in the morning, afternoon and evening for each gender. Significant differences were observed in the anxiety level in males when comparing T1 and T3 $(p<0.05$; Figure 4D) and depression level when comparing T2 and T3 $(p<0.01$; Figure 4F) that were determined by using BDI-II. There was no significant difference observed comparing data between male and female concerning MRSs (Figure 4D-F).

Table 5 shows Cohen's (d) ES of MRSs that computed between the T1 and T3. The ES concerning HADS-A was medium in all participants, large in males only and small in females only. The ES of 
HADS-D was small in all participants, in males only and females only. Meanwhile, the ES of BDI-II was at a medium level in all participants, in males only and females only.
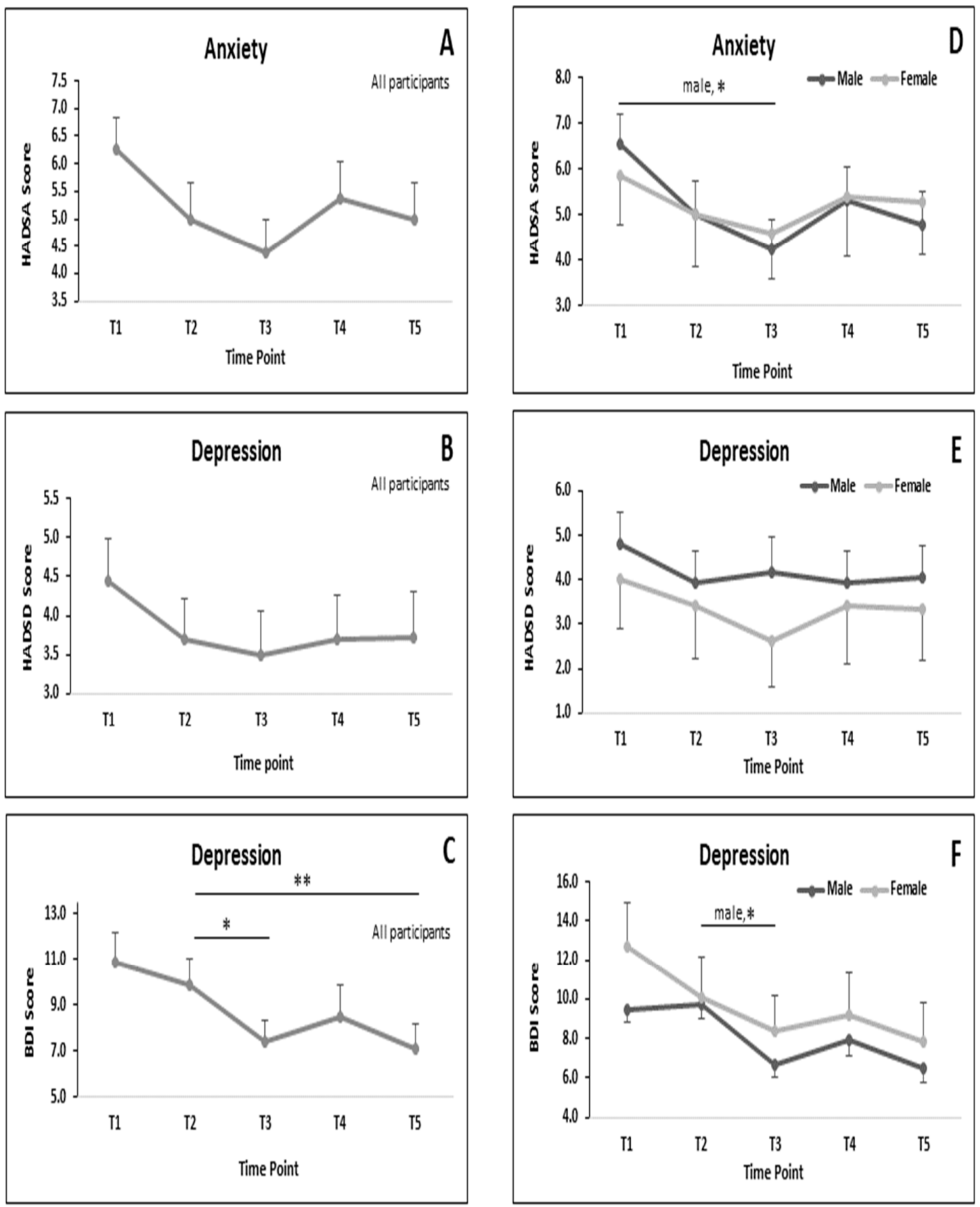

Figure 4. Patterns of MRSs during RF. (A-C) All participants; (D-F) subgroup male and female. Data presented in mean and SEM. ${ }^{*} p<0.05 ;{ }^{* *} p<0.01$.

Table 5. Cohen's ES of MRSs between T1 and T3.

\begin{tabular}{cccc}
\hline & \multicolumn{3}{c}{ ES Cohen's (d) } \\
\cline { 2 - 4 } & All Participants & Male & Female \\
\hline HADS-A & 0.54 & 0.80 & 0.31 \\
HADS-D & 0.29 & 0.18 & 0.43 \\
BDI-II & 0.54 & 0.58 & 0.54
\end{tabular}

Note: ES: effect size; HADS-A/D—hospital and anxiety depression scale-anxiety/depression; BDI-II—Beck's depression inventory. 


\section{5. $B C$ during $R F$}

\subsubsection{All Participants}

BC parameters of all participants are demonstrated in Figure 5. BW and BMI significantly decreased almost at every time point (Figure 5A,B) when compared to the baseline T1. It also showed a significant decrease when compared $\mathrm{T} 2$ and $\mathrm{T} 3$ in both BW and BMI. The significant differences in SMM, FFM, BWM and BMR (Figure 5E-H) were only observed when comparing T1 and T3; and T1 and T4. Meanwhile, there was no significant difference in BFM and BFP (Figure 5C,D).
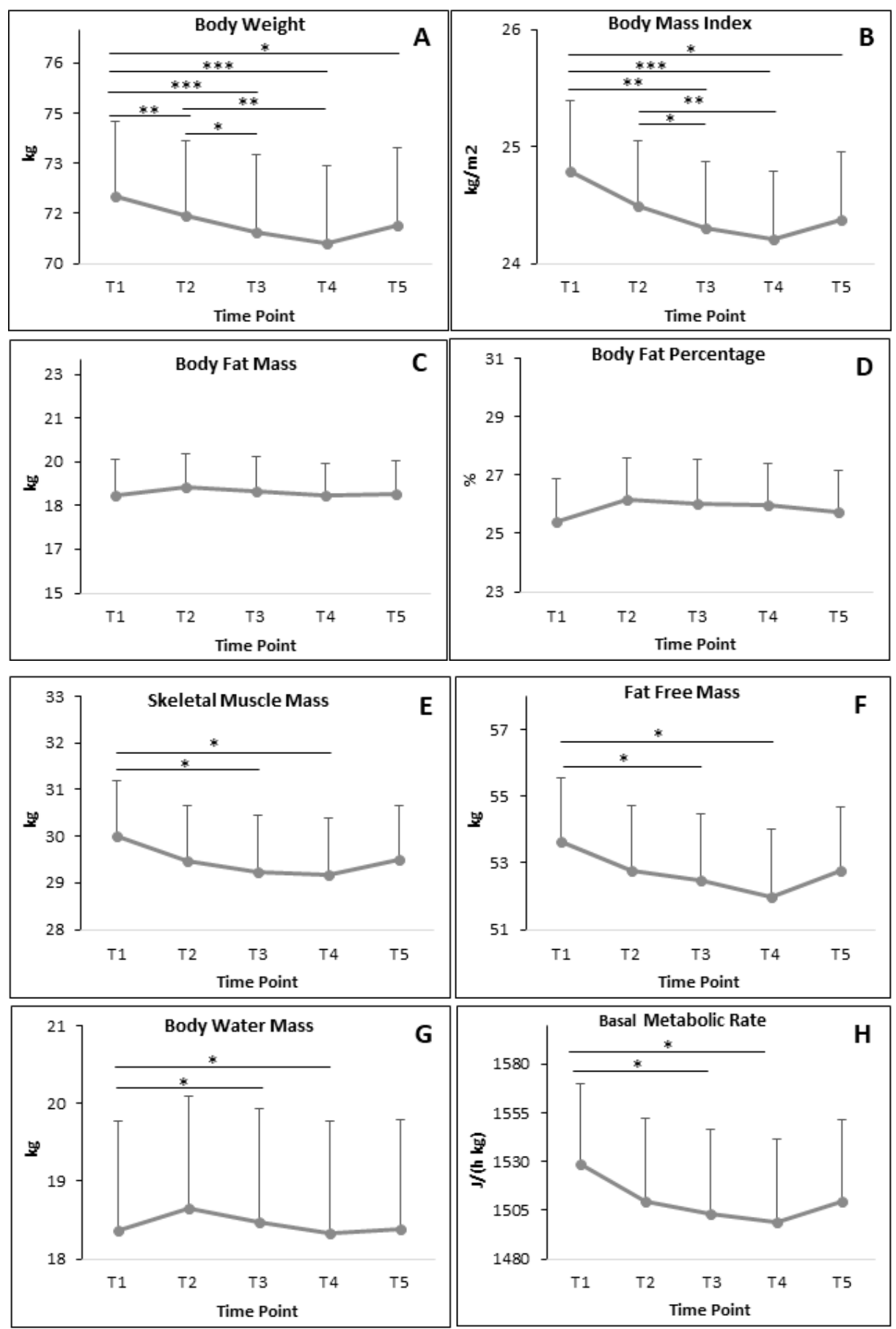

Figure 5. The alteration of BC parameters during RF in all participants (A: body weight; $\mathbf{B}$ : body mass index; C: body fat mass; D: body fat percentage; E: skeletal muscle mass; F: fat free mass; G: body water mass; H: basal metabolic rate). Data presented in mean and SEM. ${ }^{*} p<0.05 ;{ }^{* *} \mathrm{p}<0.01 ;{ }^{* * *} p<0.001$. 
Table 6 demonstrates the ES of BC parameters of all participants between T1 and T3. The ES of all BC parameters in all participants were low (Table 6).

Table 6. Cohen's ES (d) of BC parameters of all participants between T1 and T3.

\begin{tabular}{cc}
\hline & ES Cohen's (d) \\
\hline BW & 0.08 \\
BMI & 0.14 \\
SMM & 0.11 \\
BFM & 0.02 \\
FFM & 0.10 \\
BFP & 0.07 \\
BWM & 0.10 \\
BMR & 0.10
\end{tabular}

Note: ES—effect size; BMI—body mass index; BFP—body fat percentage; BW-body weight; BWM—body water mass; SMM—skeletal muscle mass; BFM—body fat mass; FFM—fat-free mass; BMR—basal metabolic rate.

\subsubsection{BC Parameters in Subgroup of Male and Female during RF}

Figure 6 demonstrates the results of different BC parameters in males and females. In males, significant reductions were only observed in BW and BMI, particularly when comparing T1 and T3; and T1 and T4, respectively. In females, BW and BMI significantly decreased when comparing T1 with all other time points. A similar pattern of significant differences was also observed in BMI of females, except when comparing T1 and T5. BFM and BFP were not significantly different in both males and females along the study.

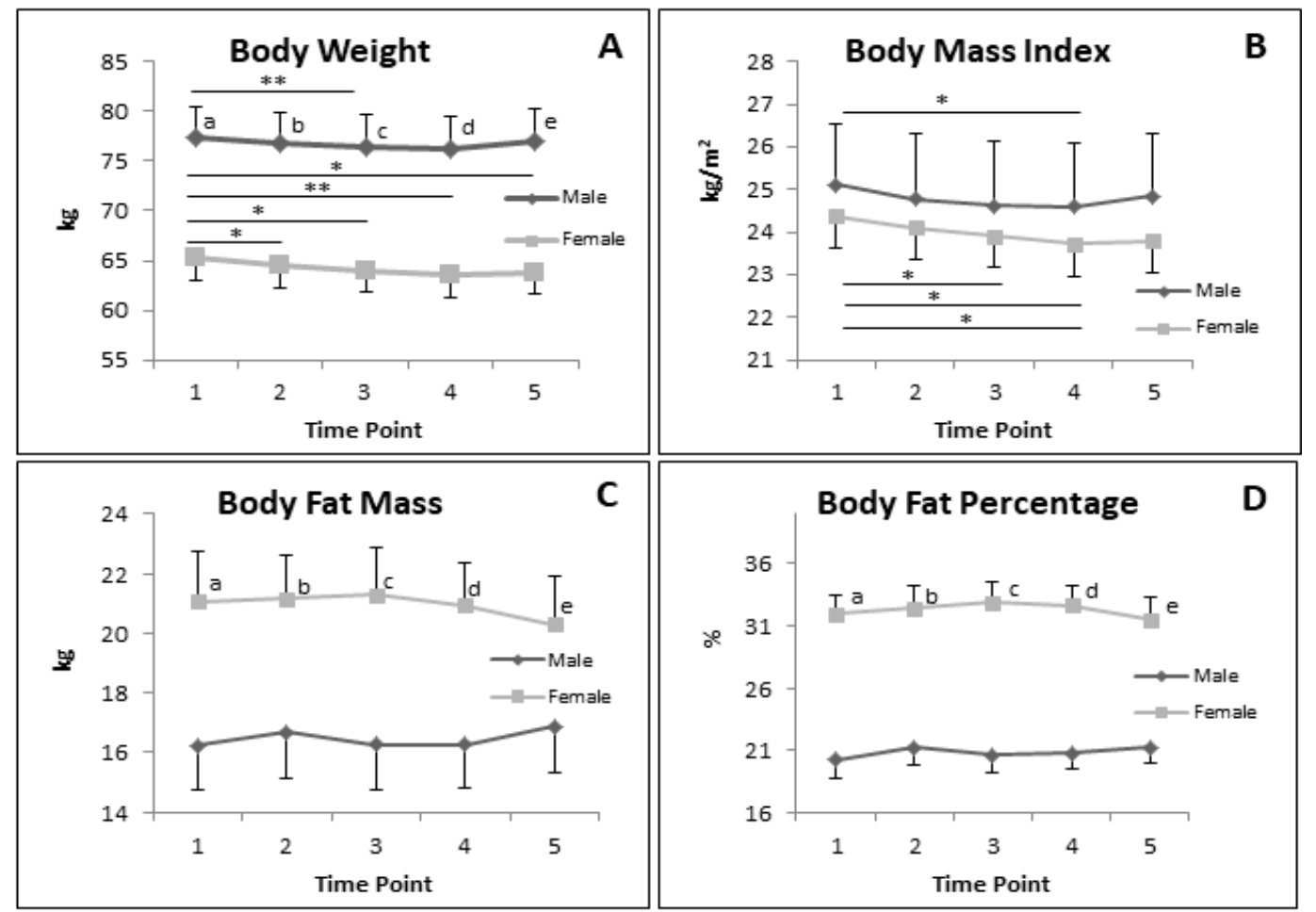

Figure 6. Cont. 


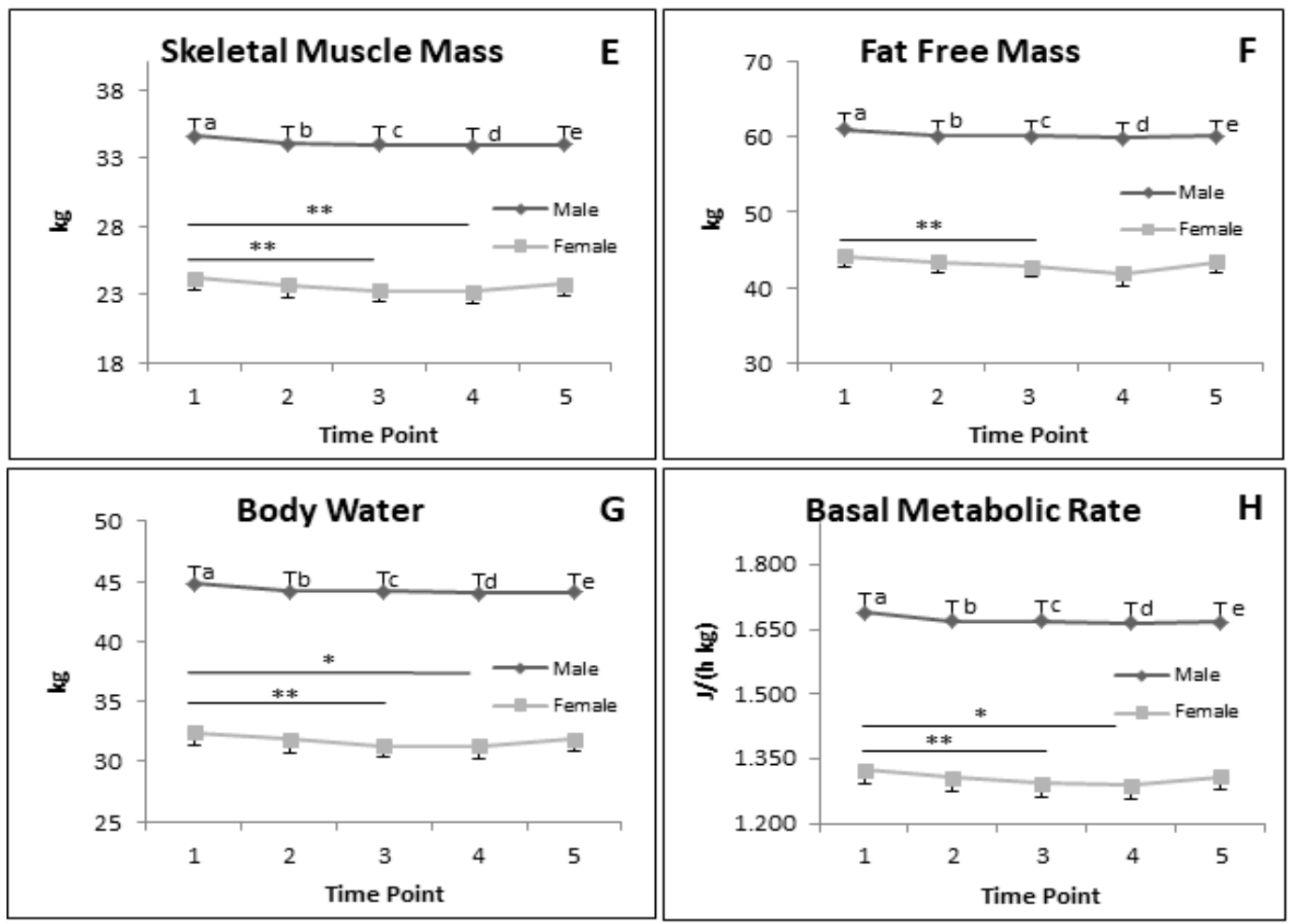

Figure 6. Alteration of BC during RF in subgroup male $(n=19)$ of and female $(n=15)$. (a-e) significant difference between male and female at T1, T2, T3, T4 and T5, respectively. (A: Body weight; B: Body mass index; C: Body fat mass; D: Body fat percentage; E: Skeletal muscle mass; F: Fat free mass; G: Body water mass; H: Basal metabolic rate). Data presented in mean and SEM. ${ }^{*} p<0.05 ;{ }^{* *} p<0.01$.

The significant decrease of SMM, FFM, BWM and BMR were only observed in females. The SMM, BWM and BMR were significant differences when comparing T1 and T3 and T1 and T4 (Figure 6E,G,H). The FFM of female significantly decreases when comparing T1 and T3 (Figure 6F).

All these body composition parameters, except BMI, were significantly different when comparing male and female at $\mathrm{T} 1, \mathrm{~T} 2, \mathrm{~T} 3, \mathrm{~T} 4$ and $\mathrm{T} 5$.

Table 7 shows the ES of all BC parameters between T1 and T3. The ES of males and females of all $\mathrm{BC}$ parameters computed from $\mathrm{T} 1$ and $\mathrm{T} 3$ were low.

Table 7. Cohen's (d) ES of BC parameters between T1 and T3.

\begin{tabular}{ccc}
\hline & \multicolumn{2}{c}{ ES Cohen's d } \\
\cline { 2 - 3 } & Male & Female \\
\hline BW & 0.06 & 0.14 \\
BMI & 0.13 & 0.16 \\
SMM & 0.12 & 0.30 \\
BFM & 0.00 & 0.04 \\
FFM & 0.10 & 0.27 \\
BFP & 0.05 & 0.15 \\
BWM & 0.10 & 0.27 \\
BMR & 0.10 & 0.27
\end{tabular}

Note: ES—effect size; BMI—body mass index; BFP—body fat percentage; BW—body weight; BWM—body water mass; SMM—skeletal muscle mass; BFM—body fat mass; FFM—fat-free mass; BMR—basal metabolic rate.

\section{Discussion}

The main objectives of this study wat to determine the effect of RF on fatigue in young male and female participants. Additionally, sleepiness, MRSs and BC parameters were also determined. 
It was performed in Germany in 2017 where RF was conducted for about 17-18 h/day, due to the summer time.

\subsection{Fatigue and Sleepiness}

As aforementioned, fatigue is one of important parameters that one should be control in order to have good performance in conducting daily activities. As prolonged fasting, like RF, could also affect the performance of daily activities, it is of important to determine the level of fatigue in different time points (morning, afternoon, evening) during RF. Additionally, the sleepiness score was also measured at similar time points.

Significant alterations of fatigue in all participants (the combination of male and female) were observed in the morning and evening time, but not in the afternoon. The alterations were positive-i.e., resulted in a decrease of fatigue. The pattern of alterations of fatigue is quite interesting, the afternoon and evening are similar and tend to decrease until T5. Meanwhile, the morning pattern tends to decrease until T4 and turns back to the baseline level at T5. The resulting study was in agreement with a previous study that showed the improvement of fatigue score in male participants that were measured in the morning [16]. The latter study was only measured until one week after RF (T4). Therefore, our results added new information that the effect of RF on fatigue could only reach until one week after RF. It could be that participants already back to their usual life style one week after RF. This study shows contradictory than the other studies that was done in nurse [19] and elite male judo athletes [30]. In the two latter studies, fatigue levels were increased. It could be that characteristic and activities of participants were different. Another reason could be that the different of assessment tools. Piper fatigue scale and fatigue abbreviated questionnaire were used in the two latter study, respectively $[19,30]$ and FSS in this study.

Sleepiness score was determined by using ESS, which is a validated instrument to evaluate the likelihood that participants will fall asleep during certain activities [28]. The sleepiness score of all participants and also in the only males as well as in the only females in this study was not significantly different. This was in agreement with Bahammam et al. [31] that showed no effect on ESS, but in contrast with the previous study that showed gradual improvement [16]. One of the reasons could be that the latter study studied only male participants; and in the current study, there were no significant differences in male participants only. The sample size could be another reason this study contrasted with the previously referenced study. The current study had about $24 \%$ less participants (male only) than compared to the previous study [16].

\subsection{Mood-Related Symptoms}

MRSs were determined by using HADS-A for anxiety, HADS-D and BDI-II for depression. There was a tendency of improvement of the anxiety score of all participants-in males as well as females. However, the significant difference was only observed in male participants. This is consistent with the previous study that showed significant improvement in male participants [16].

The significant improvement of depression score was observed in all participants and in the only males, but not in the only females. This result is consistent with previous studies (References that showed significant improvement in male participants [16,32] and in only BDI-II as an assessment tool, but not in HADS-D [16]. It is known that BDI-II is more sensitive to the alteration of depression in cross-cultural studies [33]. Our results also show that the effect of RF on depression score could be lasted until one month after RF. Improvement of mood which was measured by using BDI-II was also observed in 2-year study of calorie restriction [34].

\subsection{BC Parameters}

BW and BMI of all participants were significantly reduced at all times when compared to before RF (T1). The effect could also still be observed until one month after RF (T5). The results of this study 
are consistent with other studies [16,35-37]. In spite of contradictory to other studies that could not show significant differences during RF $[38,39]$.

Concerning SMM and FFM, it seems not only 18 to $19 \mathrm{~h}$ of fasting, but also from $17 \mathrm{~h}$ of fasting could start to reduce the SMM significantly. Fasting could increase the gluconeogenesis that leads to protein breakdown $[40,41]$. However, this result was interesting, as the significant reduction of SMM, FFM and BWM could only be observed in female participants, not in male participants. A previous study reported the reduction of muscle mass in males was observed in fasting for about 18-19 $\mathrm{h}[16,35]$. Some studies agree that there are no differences in protein metabolism of adult men and women [42,43]. However, in certain conditions, like prolonged fasting, it seems the gluconeogenesis with proteolysis of protein is faster in females than males, as it is shown in this study. Further study needs to be performed to elucidate this mechanism.

Subgrouping analysis based on gender, the significant reduction of SMM, FFM, BW and BMR were only observed in females, not in male participants. This is an agreement with Bahammam et al. [44] that showed a reduction of female resting metabolism rate during fasting day as compare to non-fasting day.

\subsection{Effect Size}

The ESs of fatigue, sleepiness, MRSs and BC parameters were only computed between T1 and T3, as it was supposed that T3 (last days of RF) could be the most interesting point that could lead to the highest effect during RF. Our results showed that medium to large effects were observed particularly for MRSs, particularly BDI-II and HADS-A, respectively. These also could lead to the conclusion that the benefit of RF particularly could be seen in the MRSs.

To the best of our knowledge, this is the first study that reported the effect of fatigue in males and females during RF in three different times: morning, afternoon and evening. This is also the first study that reported, medium and large ES of long fasting period (17 h/day) on MRSs.

Limitations of this study. In this study, there was no control group (non-fasting group) to be compared with the fasting group. It was decided as in our previous study there were no group differences between fasting and non-fasting groups in all the above-mentioned parameters [16]. However, in the future it would be of interest to perform another study by comparing it with the non-fasting group with both genders. Another limitation is related to the age group of participants who are mostly young: almost all are university students. In this study, the activities of participants and other circumstances (e.g., daily activities, sport and exam periods) were not recorded. It would be relevant and of importance to, in the future, take into accounts these parameters. Considering the effect of RF could be different in different age groups, future studies should consider recruiting older participants, too. The food intake was not monitored, as we would like to observe the real-life situation of participants during RF. It would be important to monitor food intake, as dietary diversity and food pattern could be different during RF $[45,46]$.

\section{Conclusions}

In summary, engaging in RF could result in various benefits to young males and females, including a decrease in fatigue and improvement of MRSs.

Author Contributions: Conceptualization, B.N.; methodology, B.N., A.R., S.K.G., L.E., C.G.; validation, B.N., A.R.; formal analysis, B.N., A.R., S.K.G.; investigation, B.N., A.R., S.K.G., L.E.; resources, B.N., C.G.; data curation, A.R., L.E.; writing-original draft preparation, B.N., A.R., S.K.G.; writing-review and editing, B.N.,A.R., S.K.G., L.E., C.G.; visualization, B.N., A.R., C.G.; supervision, B.N., C.G.; project administration, A.R., L.E., S.K.G.; funding acquisition, C.G. All authors have read and agreed to the published version of the manuscript.

Funding: This research received no external funding.

Acknowledgments: We would like to thank Ali Tehrani as a native English speaker who checked and corrected this manuscript.

Conflicts of Interest: The authors declare no conflicts of interest. 


\section{References}

1. Patterson, R.E.; Laughlin, G.A.; LaCroix, A.Z.; Hartman, S.J.; Natarajan, L.; Senger, C.M.; Martinez, M.E.; Villasenor, A.; Sears, D.D.; Marinac, C.R.; et al. Intermittent Fasting and Human Metabolic Health. J. Acad. Nutr. Diet. 2015, 115, 1203-1212. [CrossRef]

2. Cho, Y.; Hong, N.; Kim, K.W.; Cho, S.J.; Lee, M.; Lee, Y.H.; Lee, Y.H.; Kang, E.S.; Cha, B.S.; Lee, B.W. The Effectiveness of Intermittent Fasting to Reduce Body Mass Index and Glucose Metabolism: A Systematic Review and Meta-Analysis. J. Clin. Med. 2019, 8, 1645. [CrossRef]

3. Domaszewski, P.; Konieczny, M.; Pakosz, P.; Baczkowicz, D.; Sadowska-Krepa, E. Effect of a Six-Week Intermittent Fasting Intervention Program on the Composition of the Human Body in Women over 60 Years of Age. Int. J. Environ. Res. Public Health 2020, 17, 4138. [CrossRef]

4. Grajower, M.M.; Horne, B.D. Clinical Management of Intermittent Fasting in Patients with Diabetes Mellitus. Nutrients 2019, 11, 873. [CrossRef]

5. Malinowski, B.; Zalewska, K.; Wesierska, A.; Sokolowska, M.M.; Socha, M.; Liczner, G.; Pawlak-Osinska, K.; Wicinski, M. Intermittent Fasting in Cardiovascular Disorders-An Overview. Nutrients 2019, 11, 673. [CrossRef]

6. Eldeeb, A.A.; Mahmoud, M.A.; Ibrahim, A.B.; Yousef, E.A.; Sabry, A.A. Effect of Ramadan fasting on arterial stiffness parameters among Egyptian hypertensive patients with and without chronic kidney disease. Saudi J. Kidney Dis. Transpl. 2020, 31, 582-588. [CrossRef]

7. Mittelman, S.D. The Role of Diet in Cancer Prevention and Chemotherapy Efficacy. Annu. Rev. Nutr. 2020, 40, 1-25. [CrossRef]

8. Mattson, M.P.; Longo, V.D.; Harvie, M. Impact of intermittent fasting on health and disease processes. Ageing Res. Rev. 2017, 39, 46-58. [CrossRef]

9. Mattson, M.P.; de Cabo, R. Effects of Intermittent Fasting on Health, Aging, and Disease. Reply. N. Engl. J. Med. 2020, 382, 1773-1774. [CrossRef]

10. Anton, S.D.; Moehl, K.; Donahoo, W.T.; Marosi, K.; Lee, S.A.; Mainous, A.G.; Leeuwenburgh, C.; Mattson, M.P. Flipping the Metabolic Switch: Understanding and Applying the Health Benefits of Fasting. Obesity 2018, 26, 254-268. [CrossRef]

11. Khedkar, P.H. Intermittent fasting-The new lifestyle? Acta Physiol. (Oxf.) 2020, e13518-e13520. [CrossRef]

12. Alghamdi, A.S.; Alghamdi, K.A.; Jenkins, R.O.; Alghamdi, M.N.; Haris, P.I. Impact of Ramadan on Physical Activity and Sleeping Patterns in Individuals with Type 2 Diabetes: The First Study Using Fitbit Device. Diabetes Ther. 2020, 11, 1331-1346. [CrossRef] [PubMed]

13. Hassanein, M.; Akif Buyukbese, M.; Malek, R.; Pilorget, V.; Naqvi, M.; Berthou, B.; Shaltout, I.; Kumar Sahay, R. Real-world safety and effectiveness of insulin glargine $300 \mathrm{U} / \mathrm{mL}$ in participants with type 2 diabetes who fast during Ramadan: The observational ORION study. Diabetes Res. Clin. Pract. 2020, 108113-108189. [CrossRef] [PubMed]

14. Khazneh, E.; Qaddumi, J.; Hamdan, Z.; Qudaimat, F.; Sbitany, A.; Jebrin, K.; Sawalmeh, O.; Abuiram, Y.; Shraim, M. The effects of Ramadan fasting on clinical and biochemical markers among hemodialysis patients: A prospective cohort study. PLoS ONE 2019, 14, e0218745. [CrossRef]

15. Adawi, M.; Watad, A.; Brown, S.; Aazza, K.; Aazza, H.; Zouhir, M.; Sharif, K.; Ghanayem, K.; Farah, R.; Mahagna, H.; et al. Ramadan Fasting Exerts Immunomodulatory Effects: Insights from a Systematic Review. Front. Immunol. 2017, 8, 1144-1157. [CrossRef]

16. Nugraha, B.; Ghashang, S.K.; Hamdan, I.; Gutenbrunner, C. Effect of Ramadan fasting on fatigue, mood, sleepiness, and health-related quality of life of healthy young men in summer time in Germany: A prospective controlled study. Appetite 2017, 111, 38-45. [CrossRef]

17. Ghashang, S.K.; Hamdan, I.; Lichtinghagen, R.; Gutenbrunner, C.; Nugraha, B. Alterations of Brain-Derived Neurotrophic Factor and Creatinine During Ramadan Fasting: A Prospective, Controlled Clinical Trial. Iran. Red Crescent Med. 2019, 21, e88324-e88328. [CrossRef]

18. Al-Barha, N.S.; Aljaloud, K.S. The Effect of Ramadan Fasting on Body Composition and Metabolic Syndrome in Apparently Healthy Men. Am. J. Mens. Health 2019, 13, 1-8. [CrossRef]

19. Ovayolu, O.; Ovayolu, N.; Tasan, E. Does Ramadan Fasting Affect Fatigue in Nurses? Holist. Nurs. Pract. 2016, 30, 222-226. [CrossRef] 
20. Fekih, S.; Zguira, M.S.; Koubaa, A.; Masmoudi, L.; Bragazzi, N.L.; Jarraya, M. Effects of Motor Mental Imagery Training on Tennis Service Performance during the Ramadan Fasting: A Randomized, Controlled Trial. Nutrients 2020, 12, 1035. [CrossRef]

21. Pak, I.E.; Cug, M.; Volpe, S.L.; Beaven, C.M. The effect of carbohydrate and caffeine mouth rinsing on kicking performance in competitive Taekwondo athletes during Ramadan. J. Sports Sci. 2020, 38, 795-800. [CrossRef]

22. Madkour, M.I.; El-Serafi, A.T.; Jahrami, H.A.; Sherif, N.M.; Hassan, R.E.; Awadallah, S.; Faris, M.A.E. Ramadan diurnal intermittent fasting modulates SOD2, TFAM, Nrf2, and sirtuins (SIRT1, SIRT3) gene expressions in subjects with overweight and obesity. Diabetes Res. Clin. Pract. 2019, 155, 107801. [CrossRef] [PubMed]

23. Ajabnoor, G.M.; Bahijri, S.; Shaik, N.A.; Borai, A.; Alamoudi, A.A.; Al-Aama, J.Y.; Chrousos, G.P. Ramadan fasting in Saudi Arabia is associated with altered expression of CLOCK, DUSP and IL-1alpha genes, as well as changes in cardiometabolic risk factors. PLoS ONE 2017, 12, e0174342. [CrossRef] [PubMed]

24. Sadeghniiat-Haghighi, K.; Yazdi, Z. Fatigue management in the workplace. Ind. Psychiatry J. 2015, $24,12-17$. [CrossRef] [PubMed]

25. Avlund, K.; Damsgaard, M.T.; Schroll, M. Tiredness as determinant of subsequent use of health and social services among nondisabled elderly people. J. Aging Health 2001, 13, 267-286. [CrossRef]

26. Valko, P.O.; Bassetti, C.L.; Bloch, K.E.; Held, U.; Baumann, C.R. Validation of the fatigue severity scale in a Swiss cohort. Sleep 2008, 31, 1601-1607. [CrossRef]

27. Valet, M.; Stoquart, G.; Glibert, Y.; Hakizimana, J.C.; Lejeune, T. Is fatigue associated with cardiorespiratory endurance among patients suffering from multiple sclerosis? Ann. Phys. Rehabil. Med. 2016, 59S, e41. [CrossRef]

28. Xiong, Y.; Zhou, X.J.; Nisi, R.A.; Martin, K.R.; Karaman, M.M.; Cai, K.; Weaver, T.E. Brain white matter changes in CPAP-treated obstructive sleep apnea patients with residual sleepiness. JMRI 2016, 1371-1378. [CrossRef]

29. Wang, Y.P.; Gorenstein, C. Psychometric properties of the Beck Depression Inventory-II: A comprehensive review. Revista brasileira de psiquiatria 2013, 35, 416-431. [CrossRef]

30. Chaouachi, A.; Coutts, A.J.; Chamari, K.; Wong del, P.; Chaouachi, M.; Chtara, M.; Roky, R.; Amri, M. Effect of Ramadan intermittent fasting on aerobic and anaerobic performance and perception of fatigue in male elite judo athletes. J. Strength. Cond. Res. 2009, 23, 2702-2709. [CrossRef]

31. Bahammam, A.S.; Almushailhi, K.; Pandi-Perumal, S.R.; Sharif, M.M. Intermittent fasting during Ramadan: Does it affect sleep? J. Sleep Res. 2014, 23, 35-43. [CrossRef] [PubMed]

32. Koushali, A.N.; Hajiamini, Z.; Ebadi, A.; Bayat, N.; Khamseh, F. Effect of Ramadan fasting on emotional reactions in nurses. Iran. J. Nurs. Midwifery Res. 2013, 18, 232-236. [PubMed]

33. Smarr, K.L.; Keefer, A.L. Measures of depression and depressive symptoms: Beck Depression Inventory-II (BDI-II), Center for Epidemiologic Studies Depression Scale (CES-D), Geriatric Depression Scale (GDS), Hospital Anxiety and Depression Scale (HADS), and Patient Health Questionnaire-9 (PHQ-9). Arthritis Care Res. 2011, 63, 454-466. [CrossRef]

34. Martin, C.K.; Bhapkar, M.; Pittas, A.G.; Pieper, C.F.; Das, S.K.; Williamson, D.A.; Scott, T.; Redman, L.M.; Stein, R.; Gilhooly, C.H.; et al. Effect of Calorie Restriction on Mood, Quality of Life, Sleep, and Sexual Function in Healthy Nonobese Adults: The CALERIE 2 Randomized Clinical Trial. JAMA Intern. Med. 2016, 176, 743-752. [CrossRef] [PubMed]

35. Ziaee, V.; Razaei, M.; Ahmadinejad, Z.; Shaikh, H.; Yousefi, R.; Yarmohammadi, L.; Bozorgi, F.; Behjati, M.J. The changes of metabolic profile and weight during Ramadan fasting. Singap. Med. J. 2006, 47, 409-414.

36. Norouzy, A.; Salehi, M.; Philippou, E.; Arabi, H.; Shiva, F.; Mehrnoosh, S.; Mohajeri, S.M.; Mohajeri, S.A.; Motaghedi Larijani, A.; Nematy, M. Effect of fasting in Ramadan on body composition and nutritional intake: A prospective study. J. Hum. Nutr. Diet. 2013, 26, 97-104. [CrossRef] [PubMed]

37. Rahman, M.; Rashid, M.; Basher, S.; Sultana, S.; Nomani, M.Z. Improved serum HDL cholesterol profile among Bangladeshi male students during Ramadan fasting. East Mediterr. Health J. 2004, 10, 131-137.

38. Ramadan, J. Does fasting during Ramadan alter body composition, blood constituents and physical performance? Med. Princ. Pract. 2002, 11, 41-46. [CrossRef]

39. Yucel, A.; Degirmenci, B.; Acar, M.; Albayrak, R.; Haktanir, A. The effect of fasting month of Ramadan on the abdominal fat distribution: Assessment by computed tomography. Tohoku J. Exp. Med. 2004, 204, 179-187. [CrossRef] 
40. Fahrial Syam, A.; Suryani Sobur, C.; Abdullah, M.; Makmun, D. Ramadan Fasting Decreases Body Fat but Not Protein Mass. Int. J. Clin. Endocrinol. Metab. 2016, 14, e29687-e29692. [CrossRef]

41. Bak, A.M.; Moller, A.B.; Vendelbo, M.H.; Nielsen, T.S.; Viggers, R.; Rungby, J.; Pedersen, S.B.; Jorgensen, J.O.; Jessen, N.; Moller, N. Differential regulation of lipid and protein metabolism in obese vs. lean subjects before and after a 72-h fast. Am. J. Physiol. Endocrinol. Metab. 2016, 311, E224-E235. [CrossRef]

42. Dreyer, H.C.; Fujita, S.; Glynn, E.L.; Drummond, M.J.; Volpi, E.; Rasmussen, B.B. Resistance exercise increases leg muscle protein synthesis and mTOR signalling independent of sex. Acta Physiol. (Oxf.) 2010, 199, 71-81. [CrossRef] [PubMed]

43. Fujita, S.; Rasmussen, B.B.; Bell, J.A.; Cadenas, J.G.; Volpi, E. Basal muscle intracellular amino acid kinetics in women and men. Am. J. Physiol. Endocrinol. Metab. 2007, 292,77-83. [CrossRef] [PubMed]

44. BaHammam, A.; Alrajeh, M.; Albabtain, M.; Bahammam, S.; Sharif, M. Circadian pattern of sleep, energy expenditure, and body temperature of young healthy men during the intermittent fasting of Ramadan. Appetite 2010, 54, 426-429. [CrossRef] [PubMed]

45. Ali, Z.; Abizari, A.R. Ramadan fasting alters food patterns, dietary diversity and body weight among Ghanaian adolescents. Nutr. J. 2018, 17, 75. [CrossRef]

46. Leiper, J.B.; Molla, A.M.; Molla, A.M. Effects on health of fluid restriction during fasting in Ramadan. Eur. J. Clin. Nutr. 2003, 57, 30-38. [CrossRef]

(C) 2020 by the authors. Licensee MDPI, Basel, Switzerland. This article is an open access article distributed under the terms and conditions of the Creative Commons Attribution (CC BY) license (http://creativecommons.org/licenses/by/4.0/). 